\title{
APLICAÇÃO DE UMA IMAGEM LANDSAT MSS AO ESTUDO DE CLIMA LOCAL - PANTANAL MATOGROSSENSE/MS
}

\author{
LAURENCE HUBERT ${ }^{a}$ \\ FRANCISCO DE ASSIS MENDONÇA ${ }^{\text {b }}$
}

\section{RESUMO}

A imagem do Satélite LANDSAT MSS de 12/05/1981, tendo como área o Pantanal Matogrossense Brasileiro, evidencia a existência de uma bruma dispersa longitudinalmente ao longo do Rio Paraguai (proximidades da confluência do Rio Taquari). Tal fenômeno despertou-nos a atenção face às características Topográfica e Geomorfológica do Pantanal Matogrossense (predomínio de planícies e baixas altitudes sem grandes desníveis) e a distribuição longitudinal da bruma.

A utilização de imagens do satélite LANDSAT MSS embora não sejam especificamente produzidas para um tratamento climático como as imagens METEOSAT, permitem, com melhor qualidade o tratamento de fenômenos climáticos em escala local. Contribuir para a difusão da aplicação da Teledeteção à Geografia é o objetivo básico deste.

PALAVRAS-CHAVE: Landsat MSS, Aplicação; Pantanal Matogrossense.

\section{1 - INTRODUÇÃO}

Inúmeros estudos desenvolvidos em laboratórios (teóricos), tem permitido a compreensão de vários fenômenos em geral.

No caso particular da Geografia, a recente técnica do Sensoriamento Remoto tem' proporcionado grande auxílio na investigação de determinados fenômenos. Aos estudos de

b - Professor na Universidade Estadual de Londrina/Pr e Pós-Graduando na Universidade de São Paulo. 
Climatologia especialmente, a utilização de imagens de satélites meteorológicas trouxe grande facilidade para o desenvolvimento de estudos e pesquisas em várias escalas.

Utilizando uma imagem de satélite LANDSAT MSS de 12/05/81 às 9:00h, de parte do Pantanal Matogrossense, analisou-se a ocorrência de um nevoeiro (neblina), disposto longitudinalmente sobre a confluência dos Rios Taquari e Paraguai/MS. A priori concebido como originado por um efeito sobretudo topogeomorfológico, o referido fenômeno possui relações de origem ligadas principalmente à outras características particulares do quadro natural da área.

O texto apresenta primeiramente uma caracterização climática da área em estudo; logo a seguir expõe o tratamento utilizado para as imagens de satélite bem como a análise das mesmas e, finalmente as conclusões sobre 0 fenômeno evidenciado.

\section{2 - O CLIMA DO PANTANAL}

De acordo com a classificação climática de A. Strahler, baseada nos controles climáticos, o Pantanal Matogrossense enquadra-se nos climas do tipo A, controlados por massas de ar equatoriais e tropicais, sendo tropical alternadamente úmido e seco. O tipo de tempo predominante na estação de verão do Pantanal tem origem na massa de ar equatorial continental (MEc), quente e chuvoso portanto; o inverno, a outra estação característicamente bem definida, é fortemente influenciado pela massa polar atlântica $(\mathrm{MPa})$, ali chegando quase totalmente desprovida de umidade, donde a ocorrência de invernos relativamente frescos a frios e secos. As estações intermediárias (primavera e outono) são marcadas pela presença da massa tropical atlântica (MTa) e, não obstante, incursões da MPa e MEc.

O efeito da continentalidade é deveras sensível nos climas do Pantanal sendo que a amplitude térmica anual situa-se em torno dos $6^{\circ} \mathrm{C}$ e, segundo Valverde (1972), "devido à fraca nebulosidade no inverno, a amplitude térmica se acentua; as madrugadas e manhãs são frias". Esta variação térmica é também bastante sensível durante a estação precedente, o outono, o que, associado à grande umidade do fim do período chuvoso, provoca a intensificação da evapotranspiração.

Segundo Tubelis (1984) o Pantanal Matogrossense está sujeito à ocorrência de entre 20 e 40 dias de nevoeiro por ano. O mesmo define nevoeiro como sendo "um conjunto visível de partículas em suspensão na atmosfera junto ao solo, capaz de reduzir a visibilidade horizontal". O fenômeno climático específico analisado neste breve estudo trata-se de uma neblina, pelo mesmo autor definida como "nevoeiro de partículas maiores que 60 micros que provocam o molhamento dos objetos, porque suas partículas não conseguem contorná-los e chocam-se com a sua superfície". A ocorrência destas neblinas está relacionada às diferenças de temperatura entre a superfície de evapotranspiração e a camada de ar mais próxima à esta; tal saturação se dá por diminuição da temperatura da massa de ar a qual sofre redução da capacidade de retenção do vapor d'água. A orografia, em determinados casos, é fator predominante na ocorrência dos fenômenos.
A distribuição espacial de tais nevoeiros (neblinas) não apresenta forma geométrica definida, embora na maioria das vezes, apareçam acompanhando o traçado dos vales fluviais, influenciados que são pela disposição das vertentes dos mesmos. Em lugares planos e com fraca turbulência do ar (ventos fracos), aparecem também acompanhando o vale de rios sem que a topogeomorfologia do local exerça papel oreponderante. A concentração de evapotranspiração, va riação térmica entre superfície e atmosfera e fraca movimentação do ar exercerão então principal influência.

\section{3 - TRATAMENTO E ANÁlISE DOS DADOS}

\section{a - TRATAMENTO}

O tratamento das imagens foi efetuado sob um sistema de tratamento de imagens do tipo "Triade 80", desenvolvido pela Cia. Sintra - França.

Após submeter a referida cena LANDSAT à superposição de vários canais, centrou-se a atenção a um pequeno e curioso detalhe no centro da mesma: um nevoeiro (neblina). O objetivo passou a ser então sua evidenciação e, um tratamento simples permitiu a realização do intento; para tanto procedeu-se da seguinte maneira: dentre as bandas espectrais MSS4, MSS5, MSS6 e MSS7 selecionou-se dois canais não correlacionados (MSS5 e MSS7). No canal MASS5 o nevoeiro (neblina) é muito bem evidenciado, sendo que ricas informações sobre a vegetação são obtidas no canal MSS7. A resposta espectral dos vegetais é sempre mais forte no canal "Infravermelho próximo" (PIR) que no canal visível; as zonas úmidas possuem resposta espectral mais fraca naquele (PIR) que neste (Visível), dado que a água absorve boa parte dos raios solares em tal canal. (Fig. 1)

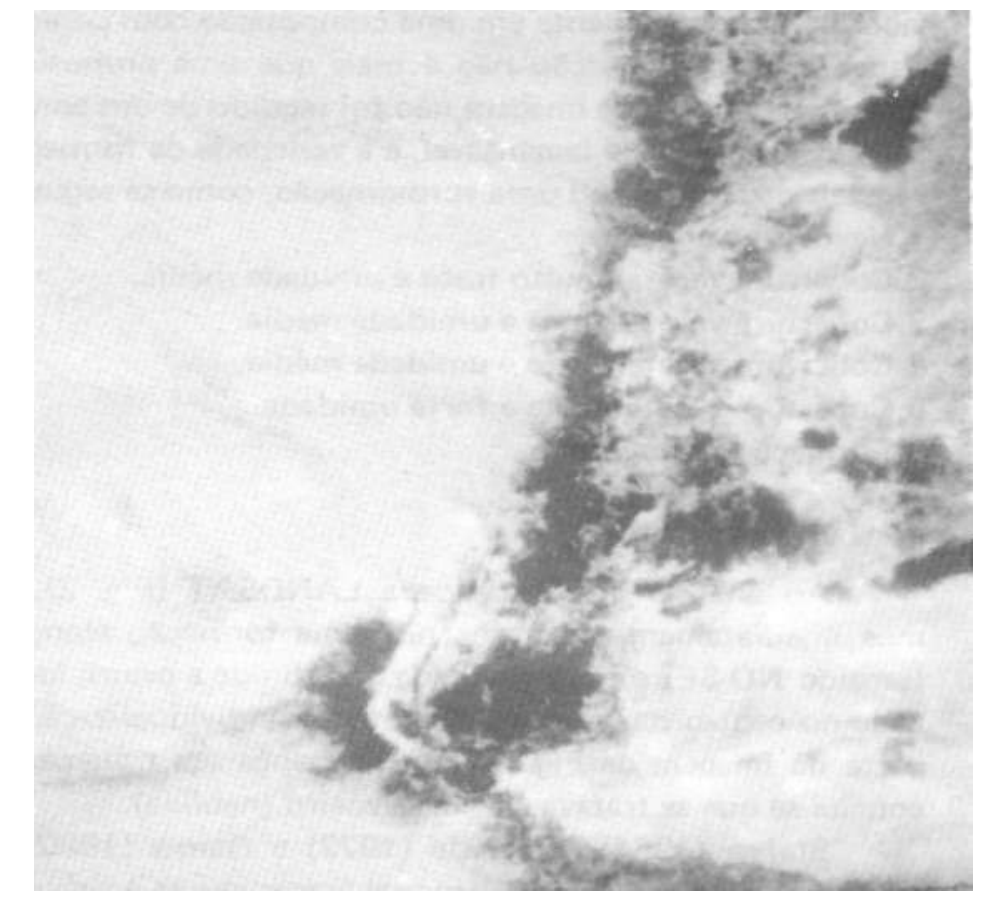




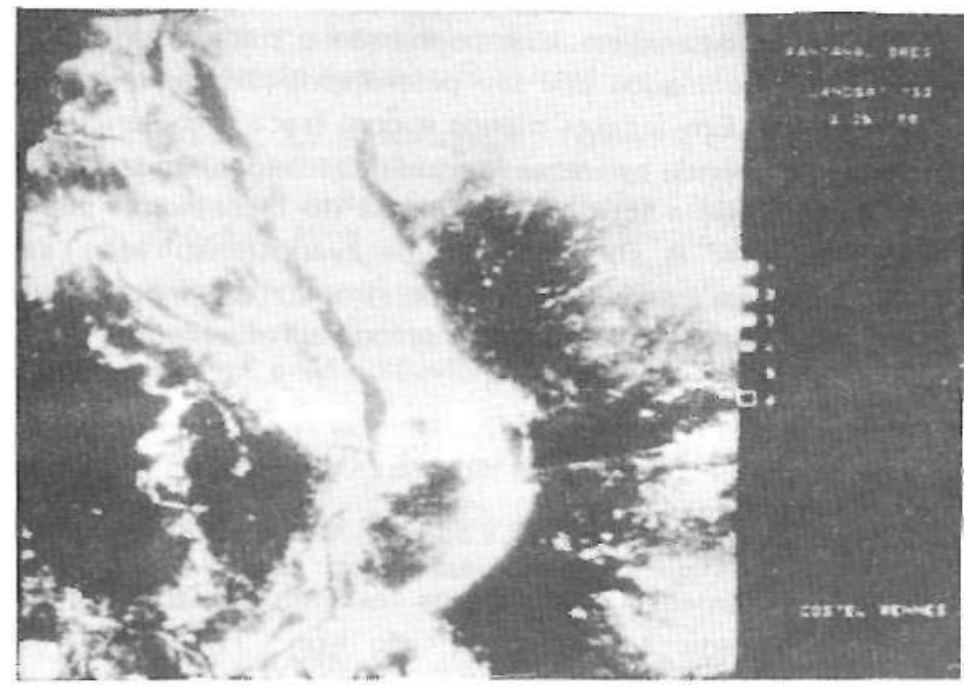

Foi necessário entretanto, calcular um indice de vegetação a fim de colocar em evidencia o nevoeiro e de obter uma classificação da cobertura do solo dado ao fato de o Pantanal Matogrossense possuir uma formação vegetal bastante complexa. Assim, o cálculo da operação $\frac{\text { MSS7 - MSS5 }}{\text { MSS7 + MSS5 }}$ permitiu acentuar os contrastes entre os tipos de vegetação, Com o resultado estabeleceu-se seis classes de ocupação do solo em função de seu teor de umidade e densidade de recobrimento do solo. Superpôs-se a esta imagem o canal MSS4 a fim de individualizar ainda mais o nevoeiro.

$\mathrm{Na}$ referida classificação, em função de se ter somente as cores do branco ao preto, não foi possível separar muito bem o nevoeiro das areias senão por sua forma; por outro lado ele é super evidente em uma composição com cores variadas. Esta classificação não é mais que uma proposição, pois o tratamento da imagem não foi seguido de um controle de campo, o que é lamentável, e a variedade de formações vegetais da área forçou uma aproximação, como se segue:

1. Nevoeiro e areias.

2. Cobertura vegetal muito fraca e umidade média,

3. Cobertura vegetal fraca e umidade média.

4. Cobertura vegetal forte e umidade média.

5. Cobertura vegetal forte e forte umidade.

6. Formação hidrográfica.

\section{b - ANÁLISE}

Ao analisar a referida cena LANDSAT (Fig. 2), fomos imediatamente atraídos por uma formação alongada (sentido NO-SE) e esbranquiçada, indefinida a priori, localizada no centro da imagem. A partir da índívidualização de parte da imagem da Fig. 1 (Fig. 2) e após seu tratamento, conclui-se que se tratava de um nevoeiro (neblina).

Stefen (1964), Valverde (1972) e Garms (1980) ao caracterizarem o clima do Pantanal fazem alusão à nebulosidade daquela área e mencionam também a ocorrência de nevoeiro, o que se certifica também em Tubelis (1984).

Entretanto, o que pareceu mais interessante foi a disposição longitudinal do nevoeiro por mais de uma dezena de quilômetros e com uma forma bastante afilada. A princípio relacionou-se tal ocorrência á influência orográfica mas, ao consultar documentos cartográficos cientificou-se da imensa planitude que é o Pantanal, que perde sua continuidade em apenas algumas elevações como a Serra da Bodoquena e o Maciço do Urucum; este último mais próximo do nevoeiro objeto de nosso estudo, porém longe do mesmo algumas dezenas de quilômetros, donde uma influência praticamente nula.

Observou-se na imagem após seu tratamento, que a concentração da umidade aparece nos locais onde a coloração é mais escura (aumentando do cinza ao negro), sendo que as cores mais claras estão relacionadas aos lugares com menor teor de umidade; vegetação menos densa, areias e solos nus; o nevoeiro foi evidenciado em cor branca.

Assim, notou-se que a origem da neblina está diretamente ligada à confluência dos rios Paraguai e Taquari que juntos proporcionam maior evaporação dado à maior extensão da superfície líquida e, à evapotranspiração da área aliadas à diferenças de temperatura superfície/atmosfera.

Tal neblina formou-se provavelmente nas primeiras horas da manhã sobre o leito fluvial como conseqüência do aquecimento superficial direto pelos raios solares, sendo que a camada da atmosfera rente ao solo encontrava-se fria - inversão térmica de superfície. A neblina, impulsionada por ventos fracos de Oeste foi levemente impulsionada em direção Leste, permanecendo portanto com sua forma afilada.

É interessante notar que ela mantém-se ainda forte em alguns de seus trechos, mesmo já sendo 9:00h; estes trechos estão diretamente ligados aos locais de maior concentração da evapotranspiração. Nos lugares onde a taxa de albedo é mais forte (areias, por exemplo), a neblina começa a sofrer dissipação.

\section{4 - CONCLUSÃO}

A utilização das imagens LANDSAT na análise da degradação ambiental e ocupação do solo tem proporcionado resultados excelentes em muitos estudos de casos, sendo esta sua finalidade principal. Para a análise de fenômenos atmosféricos, as imagens dos satélites meteorológicos são as mais apropriadas.

No presente estudo mostrou-se que em determinados casos as imagens LANDSAT MSS também se prestam à análise atmosférica, dando bons resultados na análise de fenômenos locais.

A conclusão após simples análise da imagem é de que a evapo.transpiração é o principal fator responsável pela ocorrência do nevoeiro (neblina) em questão; quanto à sua disposição longitudinal, a mesma está relacionada à estabilidade atmosférica local e concentração da umidade e vegetação situadas imediatamente sob o mesmo.

No que tange ã atividade humana, apontou-se para a necessidade da preservação da vegetação natural do Pantanal Matogrossense fato que assegurara a continuidade das trocas de energia daquele ecossistema, parte importante da biosfera terrestre. 


\section{ABSTRACT}

The LANDSAT MSS satélite image of 12/05/1981, from the Brazilian Pantanal, shows one fog disposed longitudinaly under the Paraguay River (near its Taquari River confluency); its origin is probably relative to topogeomorphology and evapotranspiration of the place. This phenomenon attracted our attention because the Pantanal topographical and geomorphological characterístics don't permit the occurence of longitudinal fog. The LANDSATT MSS satélite image utilization aren't destined to the climate studies, but, to the local climate phenomenons they can be used, like this article shows.

KEY-WORDS: Landsat MSS; Aplication; Local climate; Pantanal Matogrossense.

\section{REFERÊNCIAS BIBLIOGRÁFICAS}

1 - BARIOU, R.; LE CAMUS, D.; LE HENAFF, F. Indices de Vegetation. In: Dossiers de Télédétection, P.U.R. Université de Rennes 2 Haute Bretagne. 1985.

2 - GALVAO, M.V. (coord.) Geografia do Brasil: Regiâo Centro-Oeste. Rio de Janeiro: FIBGE, 1977.

3 - GARMS, A. O Pantanal Matogrossense e Corumbd: Roteiro de uma excursaio. IPEA/D. Geog. Humana e Regional. Presidente Prudente: UNESP, Julho, 1980.

4 - JOLY, A.B. Conheça Vegetaģa Brosileira. Să Paulo; EDUSP/Polígono, 1970.

5 - MONTEIRO, C.A.F. Geografia do Brasil: A Grande Regiāo Sul. Vol. IV. Tomo I. 2. ed. FLBGE, 1968.

6-PAUL, P. SCHEINDER, N. Télédétection des Brouillards sur le Fossé Rhénan: Premier Résultats. In: Recherches
Géographiques, n. 27. Assoc. Geogadphique d'Alsace. Strasbourg: 1987.

7 - TUBELIS, A.; NASCIMENTO. F.J.L. Meteorologia Descritiva: Fundamentos e Aplicaçores Brasilejras. Sao Paulo: NOBEL, 1984.

8 - TUCKER et TUCKER, CJ. Maximum Normalized Difference Vegetation Index Images for Sub-Saharan Africa fat 1983-1985. International Journal of Remote Sensing, vol. 7, n. 11. p. $1383-1384,1986$.

9 - VALVERDE, O. Fundamentos Geográficos do Planejamento do Município de Corumbá. Revista Brasileira de Geografia. Rio de Janeiro, 34(1). p. 49-144, Jan-Mar, 1972.

10 - AYOADE, J.O. Introduçăo da Climatologia para os Trópicos. Sāo Pauto: Difel, 1986. 